\title{
A REVIEW OF RECENT ITALIAN WORK ON RHEUMATISM
}

\author{
I.-RHEUMATIC FEVER
}

\section{By PAOLO RAVENNA}

RHEUMATIC fever (Rh.F.) has recently been the object of numerous and extensive Italian studies. These have been carried out more especially in the University Medical Clinics directed by Professors F. Micheli (Turin), Ceconi (Turin) and Frugoni (Rome), and in the Institutes of Pathology directed by Professors Pepere (Milan) and Veratti (Pavia). The point of view of the Roman school was summarised by Chini and Lusena at the Congress of the International League against Rheumatism held in Moscow in May, 1934, ${ }^{23}$ while that of the school of Micheli was explained by Andrei and myself ${ }^{9}$ in a lengthy report read before the Sixth National Congress for Microbiology held in Milan in April, 1937.

The most extensive researches have been directed towards the problem of ætiology. Some contributions to our knowledge of the clinical course, the differential diagnosis, and the pathology of the disease have also to be mentioned.

\section{Clintical Course and Pathology}

The modern conception of Rh.F. considers it as an essentially chronic and cardiac disease presenting acute articular episodes during its course (Ehrström, Swift, etc.; Micheli, ${ }^{34}$ Andrei and Ravenna9. 10). It is considered to be slightly infectious, arising not rarely in overcrowded houses (barracks, hospitals, colleges). The conception of the chronicity of Rh.F. is still disputed, and Ceconi in his treatise ${ }^{16}$ defines it as an acute disease, without, however, excluding the possibility of the contrary theory.

Rh.F. has recently been listed among the notifiable diseases in Italy, where statistical data on its frequency will be soon available. It may already be stated to be a very frequent disease in Northern Italy, especially in the regions with a continental climate. 


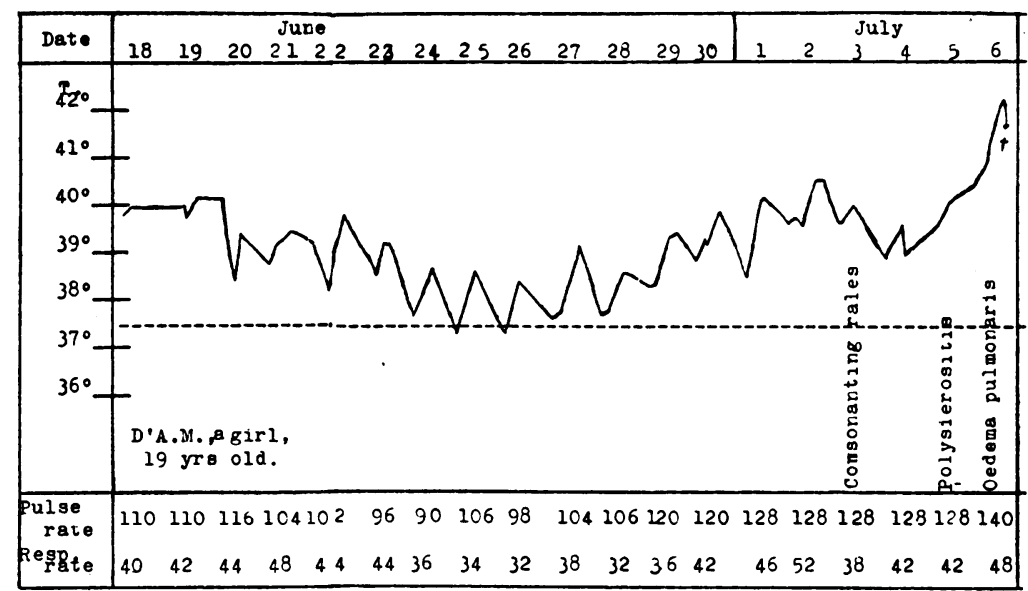

Fig. 1.-Rheumatic Pneumonia complicating Acute Carditis with Polyarthritis and Polyserositis in a NINETEEN-Year-Old Girl during the First Attack of Rheumatic Fever.

Dyspnœa was already evident when signs of cardiac failure were still missing and two weeks before the appearance of pulmonary râles. Final stage occurred with hyperpyrexia and œdema pulmonaris, and death took place four weeks after the onset of rheumatic symptoms.

(From P. Ravenna, Minerva Med., 1937.)

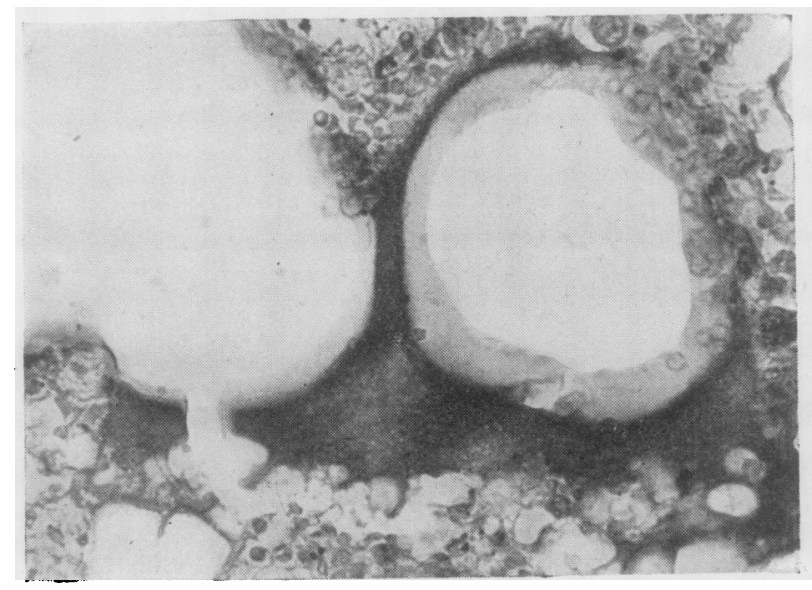

Fig. 2.-Rheumatic Pneumonia.

A view of pulmonary changes showing fibrinoid swelling in the walls of alveoles and respiratory bronchioles. Weigert's stain for fibrin. Enlarged about $\times 300$.

(From P. Ravenna, Minerva Med., 1937.) 
To the differential diagnosis of Rh.F. an important contribution has been brought by Micheli in his lectures on endocarditis lenta (subacute bacterial endocarditis). Further elements of differential diagnosis and a discussion on the relation of Rh.F. to some other diseases (sore throat, scarlet fever, serum disease, etc.) have been collected by Andrei and myself. ${ }^{2}$ The relation between Rh.F. and rheumatoid arthritis is still under discussion; most Italian authors believe that, while ætiological knowledge is still wanting, it is better to consider them as two different and autonomous diseases, though the present discrimination is based on quantitative rather than qualitative differences between the two clinical and pathological pictures, and cannot be looked upon as definite (Micheli, ${ }^{33}$ Ceconi, ${ }^{16.17}$ Andrei and Ravenna, Robecchi $^{40}$ ).

Of the contributions to the pathology of Rh.F. I must quote the descriptions of rheumatic lesions in big veins and arteries (Cellina and De Angeli, ${ }^{18}$ Agostini $^{1}$ ) and in lymphatic glands (Cassano 14. 15), a study on Aschoff's nodules (N. Andreis), and the description of rheumatic pneumonia. The pathology of this rheumatic pneumonia is interesting also because it is different from that of any other known lung disease (Ravenna ${ }^{39}$ ) (Figs. 1 and 2). A rheumatic nephritis has been described by Michelazzi and Turettini, but has been denied by Marcolongo. ${ }^{32}$

For a diagnosis based exclusively on anatomical grounds the finding of typical Aschoff's bodies is of the greatest value. In a detailed paper published in $1934 \mathrm{I}^{36}$ have shown that, in contradiction to what had been asserted by some German authors, the finding of only degenerative (fibrinoid) or monocytic-histiocytic changes is not sufficient to authorise the anatomical diagnosis of Rh.F.

\section{Ætiology and Pathogenesis}

The conception of Rh.F. as an infectious disease has never been modified in Italy, not even by the voluminous literature, especially by German and Russian authors, in favour of an exclusively allergic and non-infective pathogenesis. This theory has never been taken into serious consideration, because Italian research work is based essentially on daily clinical observation. Any theory found to be in contrast with this is looked upon with suspicion. Roessle and Klinge's allergic theory, a revival of some old observations of Weintraud and Friedberger, has been 
discussed and refuted by Micheli in a series of reports..$^{33}$ At the same time I showed on histological grounds that it is true that lesions similar to those of Rh.F. may be obtained with a more or less allergic treatment of experimental animals, but that these lesions are also obtainable with stimuli quite different from those which may be suspected in Rh.F. ${ }^{36}$ The same point has been stressed by P. Locatelli and Varcica, ${ }^{43-47}$ on the basis of their experiments.

The allergic, non-infective, theory thus having been rejected, the infectious ætiology of Rh.F. has continued to be the leading line of Italian inquiries, and all research work has always been confined to the identification of an infectious causative agent.

Tuberculous AETIOLOGY.-Discarding bacteria which have enjoyed but an ephemeral notoriety, the astonishing discovery of Reitter and Löwenstein has to be mentioned. In Italy, as everywhere, blood cultures carried out with Löwenstein's method gave only negative results (Favero, Alessi, Zuccola, Sigon, Schiavo, Arrigoni and Tronchetti, ${ }^{12}$ Silvestrini ${ }^{41}$ ). Nor is the deviation of the complement by tuberculous antigen in Rh.F. patients (frequent according to Frola and Berio, rare according to Campus) of definite value in supporting this hypothesis.

Streptococcal Attology. - Among the other known bacteria, we have to consider only the streptococcus, or the different varieties of streptococci which, replacing one another in turn, have dominated the bacteriology of Rh.F. since the times of Löffler and Sahli, and since the first researches of F. J. Poynton and Paine in England, and of Allaria in Italy.

Most attempts to demonstrate the presence of streptococci in the blood or in the joints of rheumatic patients have given completely negative results to Gamna, Andrei, Ravenna, De Vecchi, Ceresoli, Virando, Malacrea and Belleli. Others (Corelli26. ${ }^{27}$ and Chini22) observed a slight bacteræmia set up by anhæmolytic or viridans streptococci; but the ætiological value of such a finding is lowered by the possibility of an identical bacteræmia following non-rheumatic sore throat, which was proved by the same authors in coincident inquiries.

The finding of streptococci in post-mortem examinations has also very little value, because of the frequency of agonal bacterial invasions, in which streptococci are often well represented (Andrei).

Streptococci have been found constantly. only in rheumatic 
throats, where one well-defined variety of hæmolytic streptococci has been isolated with high frequency during the sore throat accompanying or preceding the onset of Rh.F. This has been established by several American and English authors, and was confirmed also by some investigations of Andrei and myself. ${ }^{2}$

Some particular pathogenic activity, especially towards the joints and heart of experimental animals, has been sought in the streptococci obtained from Rh.F. patients. A selective tropism towards the joints was the first object of inquiry. A group of experiments conducted by the school of Frugoni (Lusena, 23 Chini, ${ }^{21}$ Magrassi, Garbini, ${ }^{29}$ Spina ${ }^{42}$ ) has been interpreted as positive-i.e., demonstrating the possibility of an arthrotropism of streptococci. But with further experiments Andrei and $\mathbf{I}^{2}$ have shown that rabbits, the animals used for this kind of experiment, present such frequent arthritis following the injections of any type of pathogenic streptococci, and that their individual susceptibility to this varies so much, that it is impossible to prove an arthrotropism with Rosenow's method. A lively polemic followed, ${ }^{3}$ with the result that no Italian author has any longer sustained the possibility of an arthrotropism, and only confirmations of our conclusions have appeared (Vacirca ${ }^{43.46}$ ).

It should be noted that the most difficult point in these inquiries on tropism lies in the evaluation of the results, which should be assessed by statistical methods. Indeed, only a quantitative and not a qualitative result is of value in these experiments, because we may obtain endocarditis or arthritis with any streptococcus; the crux is whether or not some streptococci give these lesions more frequently than others. I have attempted to ascertain whether the calculus of errors may be applied to the evaluation of such results. I have proposed ${ }^{37}$ some new formulæ which are simple enough and may be useful for this purpose. They show the limits between which the errors of a certain group of experiments are probably comprised, and they enable us to compare different series of experiments, defining their relative values. The employment of these formulæ for the evaluation of experimental results on tropism leads precisely to the above-mentioned conclusions.

More involved technical procedures have been employed in further inquiries: a streptococcal focus of infection has been produced in rabbits, and some days after a suspension of the same bacteria killed has been given intravenously. This technique 
ought roughly to reproduce what may happen in human patients if a circumscribed streptococcal infection changes the body reactivity in such a manner that the successive entry into the circulation of toxins from the same focus may produce the articular and cardiac symptomatology of Rh.F. Such kinds of experiments tried by some American and Russian authors have given negative results. But Magrassi has claimed some very interesting positive results, having obtained with nearly absolute regularity a true granulomatous spread throughout many joints and in the heart, where he stressed the finding of Aschoff-similar nodules containing monocytes and histiocytes, as well as some giant cells.

Andrei and $\mathrm{I}^{4}$ repeated these attempts, with some modification in the technique, to elucidate their significance. The changes obtained by us have always been confined to the heart and to the one joint in which an injection of living streptococci had been given; widespread changes throughout many joints have been always missing. Morphologically the lesions observed by us in rabbits' hearts have been at times very similar to those of rheumatic myocarditis, but no macroscopic or microscopic endocarditis has been found. The joint lesions showed the classical features of a chronic or of a healing pyogenous infection. Further researches that we made have explained the meaning of the myocardial changes; these lesions are to be observed in rabbits following extremely diverse treatments, and also without treatment, for it is well known that rabbits are often subject to spontaneous chronic myocarditis. These changes have, however, no right to be considered as specific for any one ætiology or any one pathogenesis, and cannot serve to demonstrate the ætiopathogenesis of human Rh.F. The experiments of Andrei and myself on focal infection have been repeated and confirmed by Vacirca, ${ }^{44,45,47}$ who worked for some time in Aschoff's Pathological Institute in Freiburg. Later Chini and Magrassi ${ }^{31}$ have associated themselves with our conclusion. They have interpreted the granulomatosis obtained with focal infection in rabbits as a consequence of a mild septicæmia originating from the focus; these changes may well reproduce the picture and the pathogenesis of streptococcal rheumatism (Gräff), but have no bearing on true Rh.F.

Some positive cutaneous reactions towards streptococci and the possibility of agglutinating the streptococci with the serum of rheumatic patients have been claimed by Chini and Magrassi. ${ }^{24}$ But for the ætiological investigation of Rh.F. they are of little 
importance, because of the small number of patients studied, and because of the positive occurrence of similar reactions in non-rheumatic patients.

VIRUS AtrologY.-Direct search for a virus in the blood or other organic fluids of rheumatic patients has been attempted by Sindoni and Vitetti. In 1924 they claimed to have found a filtrable virus which in cultures was said to have the form of a diplococcus. Control inquiries by Gamna and Andrei gave negative results, and in a short time silence descended over these researches.

Another group of inquiries have been made by de Vecchi, Gennari, Natali, Vanni, Magrassi. They have injected rheumatic patients' blood into laboratory animals; the results have been either positive, but not confirmed, or negative. These attempts have been given up.

In 1932, after a thorough and critical review of the results obtained by the former authors, I proposed ${ }^{36}$ to take up these experiments again by injecting blood (or eventually other pathological material) taken from patients with Rh.F. I set down the following experimental rules: (1) Blood to be injected as soon as taken from the patient, and without being modified by anticoagulants. Whole blood and not serum to be used, as the latter is generaiiy poorer in germs. (2) Injections to be given in a cavity whence the blood may be quickly absorbed (e.g., abdominal cavity), and not in the veins, where it might produce vascular or cardiac thrombosis. (3) Rabbits appear to be the most suitable animals for large-scale researches, their viscera being big enough for an easy macroscopic examination. (4) Only young rabbits to be used, as they are usually more sensitive to infection than older ones. (5) After the injection the animals to be observed for rather a long time (at least three to four weeks), because the development of characteristic changes in Rh.F. always requires some weeks.

These researches were undertaken with the collaboration of Dr. G. Andrei, a bacteriologist, and have been carried on over five years. The results, which were published in several papers, 5. 6. 7.8.11 are based on 947 rabbits, one to two months old, which we received from diverse breeding-places of the province of Turin.

Three to four weeks after one injection of 5 to 10 c.c. per $\mathrm{kg}$. of whole blood taken from rheumatic patients and given in the 


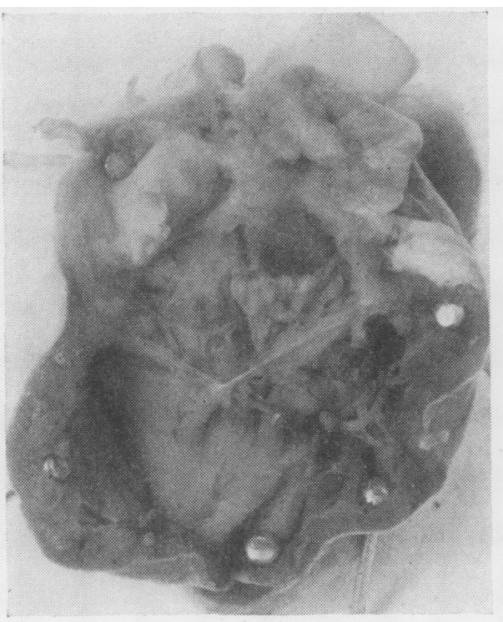

Fig. 3.

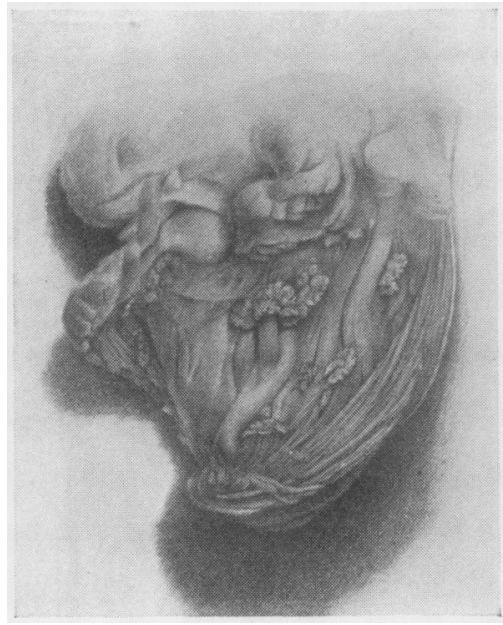

Fig. 4.

Figs. 3 and 4.-Endocarditic Lesions in the Right Ventricle RESULTING FROM THE INJECTION OF RHEUMATIC BLOOD.

Fig. 3: Heart of the rabbit, No. 354. (Slightly enlarged photograph.) Fig. 4 : Heart of the rabbit, No. 831. (Drawing from Andrei and Ravenna, Arch. of Intern. Med., 1938.)

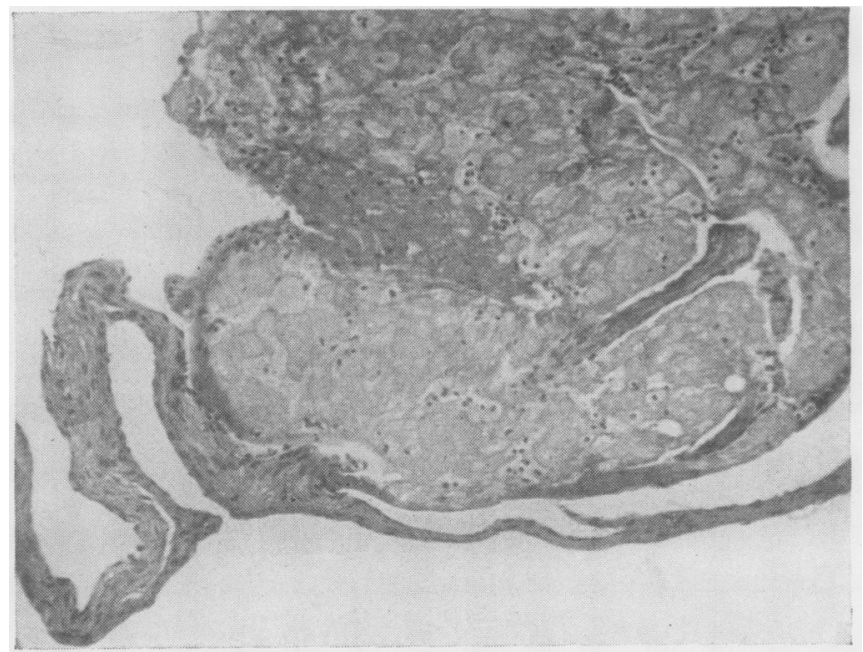

Fig. 5.- Section of a large Thrombus of the Tricuspid Valve of a RABBIT KIILEd Forty-Four Days after the INJECTION OF BLOOD FROM ENDOCARDITIC RABBIT.

Hæmatoxylin stain.

(From Andrei and Ravenna, Arch. of Intern. Med., 1938.) 
peritoneal cavity, on killing the animals a widespread endocarditis was found to be present in about 40 per cent. of the injected rabbits (Figs. 3, 4 and 5). This endocarditis is very similar to the rheumatic one, both because of its morphology and because of the constant sterility of the pathological tissues, which have been tested by routine bacteriological examination. The endocarditis may be transmitted to other rabbits by means of whole blood or filtered blood from endocarditic animals; positive serial transmission has been obtained through five successive passages. Transmission has been obtained also with a suspension containing only a small quantity of thrombotic material. The possibility of obtaining an endocarditis in non-injected rabbits kept in cages together with endocarditic ones has also been shown. No similar change, either spontaneous or experimentally induced, has been observed by the forementioned workers. Several hundreds of control rabbits have been examined concurrently with the principal experiments; they have shown that a spontaneous thrombo-endocarditis may have occurred in our animals, but so rarely that it could not modify the significance of the experiments $(0.5$ to 1 per cent.). The examination of our rabbits has always been extended to the whole body. But no change has been found, with the exception of the usual myocarditis that is frequent also in non-treated rabbits. In another series of experiments the pathogenic power of blood taken from non-rheumatic patients has been tried. It has resulted that also this blood may produce endocarditis, but with a lower frequency than the rheumatic one ( 18 per cent.). Finally, sterile milk and sterile horse serum have given positive results, and, after the usual incubation time, endocarditis appeared once again, with a high frequency ( 30 per cent.).

On this experimental evidence Andrei and I have concluded that endocarditis in rabbits is a disease which, though occasionally spontaneous, may be obtained with various treatments, consisting essentially in injection of heterogeneous protein. Its true nature should be infectious and probably contagious. The apparent sterility of viscera and blood of affected animals has enabled us to ascribe the disease to an unknown virus, probably an infravirus.

Our experiments have been controlled by Chini, ${ }^{19}$ who, in researches conducted according to our technique, has obtained the same changes. Chini has pointed out the nearly absolute 
identity of these experimental lesions with those of human rheumatic endocarditis.

The importance of these results is very difficult to estimate: opinions can but wander in the realm of hypotheses. The possibility that rabbit's endocarditis may be due to the agent of human endocarditis is hardly likely. In fact, it is possible to produce the disease in rabbits with non-rheumatic blood and with protein of proved sterility. But why, then, does rheumatic blood induce endocarditis more frequently than non-rheumatic blood? Does a substance having a special tendency to produce endocarditis exist in rheumatic blood? These are questions which further experiments may answer.

If we admit that the supposed endocarditic virus is a frequent or a constant guest of rabbits, and that it is activated by nonspecific injections of protein, may this finding have any importance for the pathogenesis of rheumatic endocarditis? A definite answer is as yet impossible; but it should be pointed out that these researches may lead to very interesting results. They should enter into a field as yet nearly unexplored, that of biotropism (activation of a latent virus by material of bacterial or nonbacterial origin). The study of biotropism, just begun in experimental animals, will probably reveal unhoped-for applications to human pathological conditions. A frequent example of biotropism in man is that which occurs in herpes febrilis; its agent, a virus which may be a harmless guest of the human body, induces herpes during some other disease, generally due to cocci (pneumococci, meningococci, etc.). Nothing excludes the supposition that a similar phenomenon may occur in Rh.F.-i.e., that a virus, which should be present and latent in the body, may become pathogenic for its guest on account of a streptococcal infection, like the sore throat which so frequently precedes the onset of rheumatic activity.

The hypothesis that the causative agent of Rh.F. is a virus, but that a symbiotic association with streptococci is more or less necessary for the onset of the disease or of its relapses, is not based solely on the results of the above-mentioned experiments. Such a conception I have already put forward three years ago, on the basis of clinical, epidemiological and bacteriological evidence..$^{35}$ It is impossible to resume here all the arguments, but I would stress its chief basis, which consisted of the results of very important work by English and American authors. 
Rh.F. begins very often following a streptococcal throat infection, but it continues a long time after the disappearance of the streptococci from the throat, showing a quite independent further development. Lately Coburn and Moore have brought forward another important argument: sulphanilamide administered to rheumatic subjects after the onset of streptococcal throat infections does not prevent rheumatism, but when taken prophylactically by rheumatic subjects who escape streptococcal infection, they do not show signs of rheumatic activity. In conclusion, these researches may show that the importance of streptococci is confined to the onset of Rh.F., because its continuation is autonomous and due to a different causative agent, the activity of which seems not to be influenced by sulphanilamide.

"The possibility of a virus ætiology has undoubtedly received more attention in Italy than in any other country " (F. J. Poynton and B. Schlesinger, "Recent Advances in the Study of Rheumatism," London, 1937), but latterly it has acquired a growing interest also in other countries. In England; Schlesinger, Signy and Amies in pathological fluids taken from rheumatic patients and submitted to high-speed centrifugation have found particles similar to those of other known virus diseases. These particles have been agglutinated by rheumatic patients' serum, but all attempts to show their pathogenic power have, up to date, been unsuccessful. In the Rockefeller Institute for Medical Research in New York, H. F. Swift, after devoting more than fifteen years to the study of the importance of streptococci in Rh.F., has attempted to inoculate the chorion-allantoic membrane of chicken embryos with rheumatic exudates. He claims to have isolated a filtrable virus. These results are as yet too recent to permit a definite conclusion.

In conclusion, it appears that the research work is actually finding its way towards the discovery of a new virus as the agent of Rh.F. The researches, which should be continued along three main avenues of inquiry, bacteriological, clinical and epidemiological, are neither easy nor rapid, but the better knowledge of a disease such as rheumatic fever, with its immense social and economic importance, is worth any effort.

(To be continued.)

For References see pp. 178-179. 


\section{REFERENCES*}

1. Agostini, A.: Lo Sperimentale, Archivio di Biologia, 1936, 90, 398-409.

2. Andrei, G., and Ravenna, P.: Boll. d. Ist. Sieroterap. Milanese, April, 1934, 13, 229-252.

3. Andrei, G., and Ravenna, P.: Ibid., July and September, 1934, 13, 543-552, 767-768.

4. Andrei, G., and Ravenna, P.: Ibid., October, 1934, 13, 804-814.

5. Andrei, G., and Ravenna, P.: Atti del $23^{\circ}$ Congresso Nazionale di Idroclimatologia, Acqui-S. Remo, Giugno, 1934, p. 133; also Rivista Idroclimat., talassol. e terap. fis., April, 1935, 46, 166-174.

6. Andrei, G., and Ravenna, P.: Acta Rheumatol., December, 1934, 6, 12-17.

7. Andrei, G., and Ravenna, P.: Giornale R. Academia di Med., Torino, July to September, 1935, II/98, 212-220; also Boll. d. Ist. Siero. terap. Milanese, August, 1935, 14, 713-726.

8. Andrei, G., and Ravenna, P.: Boll. d. Ist. Sieroterap. Milanese, March, 1937, 16, 138-149.

9. ANDREI, G., AND RAvenna, P.: "L'etiologia del reumatismo articolare acuto," Atti del $6^{\circ}$ Congr. Nazionale di Microbiologia, Milano, 1937, pp. 110-342.

10. Andrei, G., and Ravenna, P.: Giorn. di Batteriol. e Immunol., July, 1937, 19, 80-107.

11. Andrei, G., and Ravenna, P.: Arch.Internal Med., September, 1938, 62, 377-387.

12. Arrigoni and Tronchetti: Pathologica, 1934, 10, 130.

13. Battistini, S., Robecchi, A., ANd Silvani, A.: Arch.per le Sc. Med., July, 1935, 60, 173.

14. Cassano, C. : Pathologica, July 15, 1934, 26, 472-475.

15. Cassano, C.: Hamatologica, 1935, 16, No. 10.

16. Ceconi, A.: "Le malattie cosidette reumatiche," in Ceconi and Micheli's " Medicina Interna," Turin, 1936, vol. iv., pp. 1-182.

17. Ceconi, A.: "Artriti e reumatismi," Turin, 1934.

18. Cellina, M., ANd de Angeli, F.: Arch. Ist. Biochim. Ital., June, 1935, 7, 157-194.

19. Chini, V.: Boll. d. Ist. Sieroterap. Milanese, May, 1937, 16, 288-310.

20. ChInI, V.: Lo Sperimentale, Archivio di Biologia, 1934, 88, 440-455.

21. ChInI, V.: La Ricerca Scientifica, 1934, p. 495.

22. Chins, V.: Il Policlinico, sez. med., July and August, 1936, 43, 309, and 361.

23. Chini, V., And Lusena, M.: " La patologia del reumatismo dal punto di vista della infezione streptococcica e della infezione focale," Acta Rheumatol., February to May, 1934, 6, 21-23; also Policlinico, sez. prat., 1934, 41, 1241 and 1287.

24. Chini, V., and Magrassi, F.: Policlinico, sez. med., October, 1935, 42, 565.574.

25. Coari, L.: Riv. di Pat. Sperim., 1935, 15, $23-34$.

26. CoRelli, E.: Riforma Med., 1934, 50, 1449-1457.

27. CoRelli, E.: Ibid., 1935, 51, 1275-1280.

28. Erdgoni, C.: “ La clinica delle infezioni focali," in Attualità di Terapia medica, 1937, p. 236.

* References are confined to the principal papers published since 1934. Complete references to be found in Andrei and Ravenna's " Report on Ætiology of Rheumatic Fever." 
29. Garbini, R.: Giorn. di Batteriol. e Immunol., November, 1934, 13, $851-871$.

30. Graziosi, G.: Boll. d. Ist. Sieroterap. Milanese, 1936, 15, 461.

31. Magrassi, F.: Ibid., September, 1934, 13, 683-724.

32. Marcolongo, F.: Arch. per le Sc. Med., 1935, 61, 105.

33. MICHELI, F.: "Il reumatismo articolare acuto e cronico nei loro rapporti sopratutto etiologici," Atti del $23^{\circ}$ Congresso Nazionale di Idroclimatologia, Acqui-S. Remo, June, 1934; also Minerva Med., July 14, 1934, 2, 33-43; also Riv. di Idroclimatologia talassol. e terap. fis., 45, 345-369.

34. MrCheli, F.: Atti del $6^{\circ}$ Congresso Nazionale di Microbiologia, Milano, 1937, p. 375.

35. Ravenna, P.: Minerva Med., March 3, 1936, 1, 202-208.

36. Ravenna, P.: Arch. Ital. Anat. e Istol. Pat., May to June, 1934, 5, 423-456.

37. Ravenna, P.: Arch. di Patol. e Clin. Med., January, 1936, 16, 40-58.

38. Ravenna, P.: “ L'epidemiologia del reumatismo articolare acuto," Atti del $6^{\circ}$ Congr. Nazionale di Microbiologia, Milano, 1937, pp. 144-193.

39. Ravenna, P.: Minerva Med., October 14, 1937, 2, 420-428.

40. RobecCHI, A.: " La poliartrite cronica primaria," Atti del IV Congr. Italiano del Reumatismo, Milano, September, 1937; also Omnia Medica, 1938, supplem. xv.

41. Silvestrini, R.: Giorn. di Medic. Militare, January, 1935, 83, 1-10.

42. SpIna, G.: Pathologica, May 15, 1935, 27, 339-347; also Boll. d. Ist. Sieroterap. Milanese, June, 1935, 14, 550-557.

43. VActrca, F.: Boll. d. Soc. Med. Chir. Pavia, 1934, 48, 479-484.

44. VACIRCA, F.: Boll. Soc. Ital. Biol. Sper., 1934, 7, 557.

45. VACIRCA, F.: Med. Klin., November 9, 1934, 30, 1496-1498; and March 8, 1935, 31, 319-321.

46. VACIRCA, F.: Boll. d. Ist. Sieroterap. Milanese, August, 1935, 14, 727-762.

47. VACIRCA, F.: Acta Rheumatol., 1936, No. 28.

48. Virando, A., AND Bortolotit, R.: Giorn. di Batteriol. e Immunol., April, 1935, 15, 793-797.

49. Virando, A.: Giorn. di Batteriol. e Immunol., January, 1934, 12, 1-38.

50. Virando, A. : Ibid., June, 1934, 12, 1089-1120.

For the kind permission to reproduce the illustrations already published in their journals the author is gratefully indebted to the American Medical Association, the Editor of the Archives of Internal Medicine, and to the Editor of Minerva Medica. 